Article

\title{
Linking Lean Adoption and Implementation in Healthcare to National Cultures
}

\author{
Rodrigo E. Peimbert-García ${ }^{1,2, * \mathbb{C} \text {, Tapani Jorma }}{ }^{3}$, Leopoldo Eduardo Cárdenas-Barrón ${ }^{2} \mathbb{E}$, \\ Samuel M. Nucamendi-Guillén ${ }^{4}\left(\mathbb{D}\right.$ and Heriberto García-Reyes ${ }^{2}[\mathbb{C}$ \\ 1 School of Engineering, Macquarie University, Sydney, NSW 2109, Australia \\ 2 School of Engineering and Sciences, Tecnologico de Monterrey, Monterrey 64849, NL, Mexico; \\ lecarden@tec.mx (L.E.C.-B.); heriberto.garcia@tec.mx (H.G.-R.) \\ 3 Terapiatalo Noste Oy, 90100 Oulu, Finland; tapani.jorma@gmail.com \\ 4 Facultad de Ingeniería, Universidad Panamericana, Zapopan 45010, JAL, Mexico; snucamendi@up.edu.mx \\ * Correspondence: rodrigo.peimbert@tec.mx; Tel.: +61-423467860
}

check for

updates

Citation: Peimbert-García, R.E.; Jorma, T.; Cárdenas-Barrón, L.E.; Nucamendi-Guillén, S.M.; García-Reyes, H. Linking Lean Adoption and Implementation in Healthcare to National Cultures. Sustainability 2021, 13, 8855. https:// doi.org/10.3390/su13168855

Academic Editors: María del Mar Espinosa Escudero and Manuel Domínguez

Received: 4 July 2021

Accepted: 6 August 2021

Published: 8 August 2021

Publisher's Note: MDPI stays neutral with regard to jurisdictional claims in published maps and institutional affiliations.

Copyright: (c) 2021 by the authors. Licensee MDPI, Basel, Switzerland. This article is an open access article distributed under the terms and conditions of the Creative Commons Attribution (CC BY) license (https:// creativecommons.org/licenses/by/ $4.0 /)$.

\begin{abstract}
Lean Healthcare (LHC) is a widely accepted approach to improve the quality of care around the world. This research compares two studies, which evaluated the adoption/implementation of LHC in Finland and Mexico, to understand how cultural similarities/differences influence LHC implementations. Data were gathered from previous questionnaire-based studies administered to healthcare professionals in both countries. Statistics $\left(X^{2}, p\right.$, and Wilcoxon tests) are used to compare both studies across topics related to adoption, introduction, integration, success, and barriers of LHC projects, and results are linked to cultural dimensions. Driven by economic savings, LHC has been more adopted in Finland than in Mexico (75/13\%). Upon introduction, similarities are found in the way LHC projects are conducted, high project success rate, poor level of integration, and enabling/disabling factors. Conversely, differences were mainly found in the objectives of implementing LHC. These similarities/differences are linked to national factors involving culture, social structure, uncertainty management, time orientation, and indulgence level. In particular, uncertainty avoidance, equal rights' structure, and a feminine culture are positive for implementing Lean. These findings can be a benchmark to evaluate cultural practices. Thus, this study provides insight into how national cultures relate to LHC and determined distinctive sociotechnical aspects that influence its adoption/implementation.
\end{abstract}

Keywords: lean; healthcare; hospital; culture; Finland; Mexico; Scandinavia; Latin America

\section{Introduction}

Healthcare is known to be a complex industry where professionals have difficulties providing safe care while dealing with ever tighter financial constraints [1]. This has pushed healthcare leaders to support the use of Lean since the early 2000s [2]. This approach was created with a focus on manufacturing, and it has now been adopted in healthcare [3]. Some of the most diffused cases are exemplified by ThedaCare [4,5] and Virginia Mason Medical Center [6,7] in the U.S, Flinders Medical Center in Australia [8,9], and the National Health System (NHS) in the United Kingdom [10,11]. Overall, Lean implementations have resulted in improvements in quality, safety, waiting times and length of stay, flow, satisfaction, and finances [12].

Interestingly, despite the large number of Lean implementations documented around the world, mostly in the U.S. and some developed countries [13], little attention has been paid to the effect and influence the culture of these nations has over Lean implementations. Geert Hofstede has led exhaustive research to describe the culture of over 70 countries through six general dimensions: power distance, individualism, masculinity, uncertainty avoidance, and long-term orientation, and indulgence [14,15]. 
A couple of studies about Lean manufacturing literature have addressed the effect of national cultures on Lean success, but they present opposing views [16]. Within healthcare, one particular study in peer-review journals has focused on Lean and national cultures [17]. By merely classifying literature, the authors of this study compared a number of specific countries to Japan using the six dimensions, in order to make inferences about the connection between Lean in healthcare and national cultures. Therefore, even when Lean has proven to be undoubtedly transferable, there is a significant gap in research about Lean service-focused studies exploring the national culture [18]. Researchers and practitioners are still far from understanding the impact that national cultures can have on the development of Lean initiatives.

Among different types of studies that have been published in the literature (ethnographical, observational, and surveys), a survey study evaluating the level of adoption of Lean in the national healthcare system was conducted in developed countries with an individualist culture such as Finland [19]. The questionnaire developed in this study was later used to conduct a similar study in developing and collectivist countries such as Mexico [20]. These Scandinavian and Latin American countries present important similarities and differences regarding both the six cultural dimensions (described in the following section) and their national health systems. On one hand, the established Finnish public authority responsible for statistics in that country, Statistics Finland, reported a national population of 5.5 million and a total health expenditure of 20.5 billion euros in 2016 (approximately $€ 3738$ per capita). This is compounded by $74 \%$ public funding and $26 \%$ private funding, and it represents $9.5 \%$ of the gross domestic product (GDP) [21]. Additionally, the National Institute for Health and Welfare indicated the Finnish health system employed 258,567 people in municipal health and social services [22]. In contrast, the Mexican government agency INEGI (National Institute of Statistics and Geography) [23] reported a total population of approx. 120 million people ( $45 \%$ insured) and 800,000 healthcare employees. The total health expenditure nation-wide was around \$55 million USD, which is compounded of $53 \%$ public funding and $47 \%$ private and represents $5.9 \%$ of the GDP (between \$0.50-\$1.00 USD per capita approximately) [23]. Thus, this opens the question of how these economic factors and cultural similarities and differences influence the structure in which both national health systems work, and, consequently, the way Lean is introduced and implemented.

Since the literature focused on national cultures and their effect on Lean in healthcare is very scarce, a detailed comparative analysis (Finland vs. Mexico) would generate knowledge about the link between their similarities and differences, and how Lean is adopted and implemented in healthcare. The purpose of this research is, then, to compare the results obtained in the previous studies $[19,20]$, in order to both identify the similarities and differences in the adoption/implementation of Lean in healthcare and understand how these are linked to their national cultures. The five research questions addressed in this research are:

- RQ1: Is the adoption level of Lean in healthcare similar in Finland and Mexico?

- RQ2: What are the similarities and differences between the introduction of Lean healthcare in Finland and Mexico?

- RQ3: What are the similarities and differences between the levels of integration of Lean healthcare in Finland and Mexico?

- RQ4: What are the similarities and differences between the benefits of Lean healthcare in Finland and Mexico?

- RQ5: What are the similarities and differences between the factors enabling and preventing successful Lean implementations in healthcare in Finland and Mexico?

The following sections of the paper are organized as follows: A literature review is presented in Section 2, while Section 3 shows the materials and methods followed in this study. After this, Section 4 presents the comparative analysis and results, followed by a detailed discussion of results in Section 5. The last, Section 6, describes the conclusions and insights for future research. 


\section{Literature Review}

\subsection{Lean Healthcare in Scandinavian and Latin American Countries}

Lean is defined as a process improvement approach used to create value to customers while using fewer resources-doing more with less—-through five key principles: specify value, identify the value stream, flow, pull, and pursue perfection [24]. In hospitals, Lean is seen as a toolbox as well as a management system that can change the way organizations are managed [12]. Lean enables hospitals to improve the quality of care and patient satisfaction, while reducing waiting time, cost, and operational barriers [25-27]. It increases process integration and "value-added" activities for patients [28] and replaces a functional-based organization with a process-based one [29].

In a search conducted at the end of 2018, close to 35 peer-reviewed journal articles reporting on Lean healthcare in Scandinavian countries were found in medical, engineering, and business journals indexed in the following databases: Emerald Insight, Taylor \& Francis, Science Direct, Wiley, Elsevier, BioMed Central, Wolter Kluwer, BMJ, PubMed Central, Springer Link, Inderscience, Oxford Academic, Sage, IEEE Explore, and EBSCO. Two thirds of this literature correspond to studies conducted in Sweden, while the rest is evenly represented (four each) by Finland, Norway, and Denmark. Among different studies, such as literature reviews, survey studies and interviews, studies about work structure and strategies, and other studies with a general scope, nine case studies on Lean implementations were identified [28,30-37]. Specific to Finland, the first article assessed the Lean adoption in the national healthcare system in 2016 [19]. A second study collected and discussed healthcare managers' experiences with Lean through thematic interviews [38], while a third conducted a systematic review [39]. One last study presented an analysis, based on value stream mapping, that indicated Lean can also improve patient safety. [40]. In a nutshell, Lean has been applied only at an operational level-in specific processes within departments or units, with no integration between departments or larger impact-with generally positive results and occasionally negative perception [29].

On the other hand, using the same search strategy, the evidence of Lean healthcare in Latin American countries was limited to approximately 10 peer-reviewed research articles about studies conducted mainly in Brazil, including only two case studies [41,42]. Specific to Mexico, more recent research has focused on conducting literature reviews [43,44] and assessing the state of lean and six sigma practices in the national health system [20]. In 2021, one case study has focused on the use of the quick changeover approach to reduce the time to discharge patients from an internal medicine department [45]. Yet, findings suggest a limited application to specific process, which indicates Lean tends to be an isolated approach rather than a system-wide approach [25].

Although important findings have resulted from the previous studies in Scandinavian and Latin American countries, literature indicates that none have included the cultural aspect and its influence. Thus, the limited literature linking Lean in healthcare to national cultures allows for a detailed comparative analysis that could provide insights about the impact that these cultures have in how Lean is adopted and implemented in healthcare.

\subsection{Finnish and Mexican Cultures}

Geert Hofstede has conducted exhaustive research to describe the culture of 74 countries using five general dimensions: power distance, individualism, masculinity, uncertainty avoidance, and long-term orientation [14]. In addition, 39 countries have been also described using a sixth dimension, indulgence [15]. Table 1 summarizes Hofstede's findings related to Finnish and Mexican cultures. 
Table 1. Comparison of the six cultural dimensions between Finland and Mexico.

\begin{tabular}{|c|c|c|c|}
\hline \# & Definition & Finland & Mexico \\
\hline 1 & $\begin{array}{l}\text { Power distance is the extent to which the less powerful } \\
\text { members expect and accept that power is distributed } \\
\text { unequally. }\end{array}$ & $\begin{array}{l}\text { Equal rights and hierarchy } \\
\text { for convenience only }\end{array}$ & Hierarchical society \\
\hline 2 & $\begin{array}{l}\text { Individualism is the degree of interdependence a society } \\
\text { maintains among its members. }\end{array}$ & Individualist society & Collectivistic society \\
\hline 3 & $\begin{array}{l}\text { Masculinity. High score (Masc.): Society is driven by } \\
\text { competition and success. Low score (Fem.): Dominant } \\
\text { values are caring for others and quality of life, which is a } \\
\text { sign of success. }\end{array}$ & Feminine society & Masculine society \\
\hline 4 & $\begin{array}{l}\text { Uncertainty Avoidance is the extent to which the members } \\
\text { of a culture feel threatened by ambiguous or unknown } \\
\text { situations. }\end{array}$ & $\begin{array}{l}\text { Preference for avoiding } \\
\text { uncertainty }\end{array}$ & $\begin{array}{l}\text { High preference for } \\
\text { avoiding uncertainty }\end{array}$ \\
\hline 5 & $\begin{array}{l}\text { Long Term Orientation. Low score: Society prefers to } \\
\text { maintain time-honored traditions and norms. High score: } \\
\text { Society encourages thrift and efforts in modern education as } \\
\text { a way to prepare for the future. }\end{array}$ & Normative & Normative \\
\hline 6 & $\begin{array}{l}\text { Indulgence is the extent to which people try to control their } \\
\text { desires and impulses. Weak control is called "Indulgence" } \\
\text { and strong control is "Restraint". }\end{array}$ & Indulgent & Highly indulgent \\
\hline
\end{tabular}

Both countries are characterized by normative cultures where traditions are highly respected, and people focus on short term and quick results. However, there are important differences between these two countries. In Finland, there is a power decentralization, work relationships are informal, hiring/promoting are based on merit, people take care of their immediate families only, they work to live, they value quality and equality in their working lives, and negotiation is the way to resolve conflicts. Meanwhile, hierarchy and centralization at work are fundamental in Mexico, although people still are closely committed to the group; hiring/promoting consider the employee's closeness to the group, people live in order to work, there is an emphasis on competition, managers are expected to be assertive and decisive, and conflicts are solved by battling it out. Finally, both countries only have slightly differences in the degree in which they avoid uncertainty and display indulgence. For example, rules are even more needed in Mexico, people maintain more rigid codes and are less tolerant of different ideas, leisure time is more important, and people are more willing to realize their desires about enjoying life [14].

\subsection{Lean and National Cultures}

The general relationship between national cultures and Lean manufacturing has been barely studied in the literature and remains contradictory. Two studies summarize the main findings. First, a study analyzed data from the 4th Global Manufacturing Research Group's world-wide survey containing 1453 facilities, from 24 countries and 22 industry classifications. The findings of this study revealed that Lean is more effective in national cultures that value high uncertainty avoidance, short-term orientation, and low performance orientation, and that human orientation, collectivism, and power distance have no significant impact on Lean success [16]. On the other hand, a more recent study reviewed 65 research works and highlighted the Japanese culture (Lean was born in Japan as the Toyota Production System) as highly collectivist, with a long-term orientation, masculinity, strong uncertainty avoidance, and large power distance. This study concludes that traits such as long-term orientation, high collectivism, and uncertainty avoidance foster Lean, but masculinity and power distance might inhibit Lean implementation and sustainability [18].

Within healthcare, there is just one study in the literature with a focus on Lean and national cultures [17], but it is limited to a comparison of some countries with Japan, based on a classification of literature. The comparative analysis is based on the six cultural dimensions, and shallow inferences are derived about the connection between Lean in 
healthcare and national cultures. Hence, it is not clear how the cultural dimensions influence the way in which Lean is adopted and implemented in healthcare.

\section{Materials and Methods}

Herein, this research presents an analysis of similarities and differences in the levels at which Lean practices are adopted, and how projects are conducted in healthcare in Finland and Mexico. The study develops an incremental work built over data collected in two previous questionnaire-based studies. The data collection strategy used in these studies is described below.

The first study was conducted in the Finnish healthcare system, where a 27-question web-based survey (including replicated questions) was developed to evaluate the state of Lean practices in healthcare [19]. The survey instrument was developed by these authors and validated by Finnish healthcare professionals. Top management from the participating healthcare units were first contacted, and a snowball approach was used to contact potential participants [19]. The questionnaire was distributed among 248 healthcare professionals that were previously contacted by phone. Respondents include middle-level managers, supervisors, and front-line workers across 20 hospital districts and 15 major cities nationwide, from whom 110 responses were collected [19]. The second study was conducted in Mexico, where the same instrument was used, with minor adaptations, to assess the state of Lean practices in healthcare [20]. As described in the study, convenience sampling was used to select a mix of 30 public and private hospitals (those where colleagues and collaborating researchers had an established relationship of some kind). By using a snowball approach, the survey was administered face-to-face to members from different departments or units, and 278 responses were collected from middle-level managers, supervisors, and front-line workers in six different states across the country.

As part of the data curation and cleaning required to conduct this comparative study, two leading questions and two questions exclusively related to Six Sigma were dropped out of the study, as well as the answers of 18 respondents, because they provided either incomplete and unclear responses or information merely about Six Sigma, which left a total of 260 responses. The 23 questions compared in this study are shown in Appendix A.

Chi-square $\left(X^{2}\right)$, two-proportion $(p)$, and non-parametric Wilcoxon signed-rank tests (non-normally distributed data) were used to identify statistical similarities and differences between groups and answer the five research questions stated in Section 1. Since defining an hypothesis for each of the 23 questions would be exhaustive and not feasible, the authors created the least possible number of groups (5) to merge questions, based on affinity, orientation, and overall, the information that each question provides. This is how the five research questions were formulated:

- $\quad$ RQ1 focuses on the level of Lean adoption in healthcare, and it includes questions: (1) ongoing Lean projects, (4) familiarity with Lean tools, and (5) areas with the largest impact.

- RQ2 focuses on how Lean was introduced, and it includes questions: (6) timing of the first project, (7) initial reason for Lean, (8) who introduced Lean, and (16) definition of measurable goals.

- RQ3 focuses on how Lean is carried out and integrated, and it includes questions: (9) internal Lean expert and (10) his background, (11) number of Lean projects, (12) current the level of integration of Lean in the system, and (13) what tools are being used.

- RQ4 focuses on the benefits brought by implementing Lean, and it includes questions: (14) economic investment in Lean, (15) economic savings, (17) level of achievement, (18) success of Lean, and (19) main benefits. Note: although question 14 does not focus on benefits, it is relevant to assess the impact of question 15 .

- $\quad$ RQ5 focuses on enabling factors and barriers for Lean, and it includes questions: (20) enabling factors, (21) disabling factors, (22) least supportive groups, and (23) reasons of resistance. 
At the same time, the nested nature of the data is considered by clustering responses from managers and supervisors in one sub-group, and comparing them against those responses from front-line workers, question to question, with the same statistical tests. The objective is not just to isolate the effect of these sub-groups, but to analyze any existing discrepancies between them. A summary of these complementary results is presented in Appendix B. Meanwhile, the next section (results) is presented in two sub-sections. Sub-section one includes results from the first five questions where all respondents were included. Meanwhile, sub-section two presents the results of the remaining questions, where responses were provided only by healthcare professionals that have participated in Lean projects.

\section{Results}

\subsection{All Respondents}

The distribution of responses to all questions are expressed in percentages, except for questions 4 and 13, which are presented in total frequencies. These are presented in Tables 2-4, and the questionnaire can be found in Appendix A. The total number of responses slightly varies from question to question, given that some respondents skipped a couple of questions, with a median of one skipped question per respondent.

Table 2. Distribution of responses to questions 1-8.

\begin{tabular}{|c|c|c|c|c|c|c|c|c|c|c|c|c|c|c|c|c|}
\hline \multirow[b]{2}{*}{ Count. } & \multicolumn{2}{|c|}{ Q1 } & \multicolumn{2}{|c|}{ Q2 } & \multicolumn{2}{|c|}{ Q3 } & \multicolumn{2}{|c|}{ Q4 } & \multicolumn{2}{|c|}{ Q5 } & \multicolumn{2}{|c|}{ Q6 } & \multicolumn{2}{|c|}{ Q7 } & \multicolumn{2}{|c|}{ Q8 } \\
\hline & FIN & MEX & FIN & MEX & FIN & MEX & FIN & MEX & FIN & MEX & FIN & MEX & FIN & MEX & FIN & MEX \\
\hline Yes & $75 \%$ & $13 \%$ & $90 \%$ & $11 \%$ & $84 \%$ & $37 \%$ & & & & & & & & & & \\
\hline No & $25 \%$ & $87 \%$ & $10 \%$ & $89 \%$ & $16 \%$ & $63 \%$ & & & & & & & & & & \\
\hline $\mathrm{a}$ & & & & & & & 68 & 16 & $7 \%$ & $23 \%$ & $21 \%$ & $20 \%$ & $59 \%$ & $10 \%$ & $23 \%$ & $13 \%$ \\
\hline $\mathrm{b}$ & & & & & & & 75 & 27 & $7 \%$ & $27 \%$ & $40 \%$ & $20 \%$ & $27 \%$ & $77 \%$ & $21 \%$ & $22 \%$ \\
\hline c & & & & & & & 55 & 51 & $83 \%$ & $48 \%$ & $32 \%$ & $43 \%$ & $9 \%$ & $10 \%$ & $17 \%$ & $25 \%$ \\
\hline $\mathrm{d}$ & & & & & & & 28 & 5 & $4 \%$ & $2 \%$ & $8 \%$ & $17 \%$ & $5 \%$ & $3 \%$ & $22 \%$ & $38 \%$ \\
\hline $\mathrm{e}$ & & & & & & & 52 & 12 & & & & & & & $17 \%$ & $3 \%$ \\
\hline $\begin{array}{l}\text { Total } \\
\text { Resp. }\end{array}$ & 110 & 260 & 31 & 220 & 25 & 209 & 107 & 260 & 107 & 52 & 78 & 30 & 78 & 31 & 77 & 32 \\
\hline
\end{tabular}

Table 3. Distribution of responses to questions 9-16.

\begin{tabular}{|c|c|c|c|c|c|c|c|c|c|c|c|c|c|c|c|c|}
\hline \multirow[b]{2}{*}{ Count. } & \multicolumn{2}{|c|}{ Q9 } & \multicolumn{2}{|c|}{ Q10 } & \multicolumn{2}{|c|}{ Q11 } & \multicolumn{2}{|c|}{ Q12 } & \multicolumn{2}{|c|}{ Q13 } & \multicolumn{2}{|c|}{ Q14 } & \multicolumn{2}{|c|}{ Q15 } & \multicolumn{2}{|c|}{ Q16 } \\
\hline & FIN & MEX & FIN & MEX & FIN & MEX & FIN & MEX & FIN & MEX & FIN & MEX & FIN & MEX & FIN & MEX \\
\hline Yes & $74 \%$ & $42 \%$ & & & & & & & & & & & & & $59 \%$ & $83 \%$ \\
\hline No & $26 \%$ & $58 \%$ & & & & & & & & & & & & & $41 \%$ & $17 \%$ \\
\hline $\mathrm{a}$ & & & $13 \%$ & $33 \%$ & $15 \%$ & $7 \%$ & $15 \%$ & $13 \%$ & 41 & 8 & $11 \%$ & $0 \%$ & $0 \%$ & $0 \%$ & & \\
\hline $\mathrm{b}$ & & & $14 \%$ & $42 \%$ & $20 \%$ & $13 \%$ & $11 \%$ & $13 \%$ & 37 & 9 & $15 \%$ & $0 \%$ & $3 \%$ & $0 \%$ & & \\
\hline c & & & $30 \%$ & $8 \%$ & $42 \%$ & $53 \%$ & $23 \%$ & $29 \%$ & 27 & 26 & $8 \%$ & $3 \%$ & $4 \%$ & $0 \%$ & & \\
\hline d & & & $26 \%$ & $17 \%$ & $23 \%$ & $27 \%$ & $49 \%$ & $26 \%$ & 8 & 2 & $6 \%$ & $3 \%$ & $1 \%$ & $0 \%$ & & \\
\hline e & & & $17 \%$ & $8 \%$ & & & $1 \%$ & $19 \%$ & 24 & 2 & $25 \%$ & $10 \%$ & $8 \%$ & $0 \%$ & & \\
\hline $\mathrm{f}$ & & & & & & & & & & & $35 \%$ & $84 \%$ & $84 \%$ & $100 \%$ & & \\
\hline $\begin{array}{l}\text { Total } \\
\text { Resp. }\end{array}$ & 77 & 31 & 70 & $\underline{12}$ & 74 & 30 & 79 & 31 & 77 & 32 & 72 & 31 & 77 & 31 & 78 & 30 \\
\hline
\end{tabular}


Table 4. Distribution of response to questions 17-23.

\begin{tabular}{|c|c|c|c|c|c|c|c|c|c|c|c|c|c|c|}
\hline \multirow[b]{2}{*}{ Count. } & \multicolumn{2}{|c|}{ Q17 } & \multicolumn{2}{|c|}{ Q18 } & \multicolumn{2}{|c|}{ Q19 } & \multicolumn{2}{|c|}{ Q20 } & \multicolumn{2}{|c|}{ Q21 } & \multicolumn{2}{|c|}{ Q22 } & \multicolumn{2}{|c|}{ Q23 } \\
\hline & FIN & MEX & FIN & MEX & FIN & MEX & FIN & MEX & FIN & MEX & FIN & MEX & FIN & MEX \\
\hline Yes & $100 \%$ & $81 \%$ & $88 \%$ & $82 \%$ & & & & & & & & & & \\
\hline No & $0 \%$ & $19 \%$ & $12 \%$ & $18 \%$ & & & & & & & & & & \\
\hline $\mathrm{a}$ & & & & & $46 \%$ & $6 \%$ & $23 \%$ & $35 \%$ & $9 \%$ & $6 \%$ & $20 \%$ & $16 \%$ & $21 \%$ & $3 \%$ \\
\hline $\mathrm{b}$ & & & & & $29 \%$ & $77 \%$ & $31 \%$ & $32 \%$ & $14 \%$ & $23 \%$ & $51 \%$ & $34 \%$ & $25 \%$ & $47 \%$ \\
\hline c & & & & & $11 \%$ & $13 \%$ & $1 \%$ & $3 \%$ & $12 \%$ & $23 \%$ & $10 \%$ & $31 \%$ & $36 \%$ & $31 \%$ \\
\hline d & & & & & $14 \%$ & $3 \%$ & $11 \%$ & $3 \%$ & $33 \%$ & $16 \%$ & $10 \%$ & $3 \%$ & $12 \%$ & $16 \%$ \\
\hline e & & & & & & & $18 \%$ & $13 \%$ & $13 \%$ & $23 \%$ & $3 \%$ & $3 \%$ & $1 \%$ & $0 \%$ \\
\hline $\mathrm{f}$ & & & & & & & $13 \%$ & $10 \%$ & $13 \%$ & $3 \%$ & $5 \%$ & $13 \%$ & $5 \%$ & $3 \%$ \\
\hline $\mathrm{g}$ & & & & & & & $3 \%$ & $3 \%$ & $5 \%$ & $6 \%$ & & & & \\
\hline $\begin{array}{l}\text { Total } \\
\text { Resp. }\end{array}$ & 45 & 27 & 76 & 28 & 79 & 31 & 78 & 31 & 77 & 31 & 59 & 32 & 78 & 32 \\
\hline
\end{tabular}

The first five questions target random healthcare professionals, while the remaining questions are specific to respondents that have participated in Lean projects. The proportion of respondents that have had Lean healthcare projects in Finland is greater than its counterpart in Mexico (Q1), as per Figure 1. The proportion of participating managers and supervisors is also greater than the proportion of front-line workers for Q1, as shown in Appendix B.

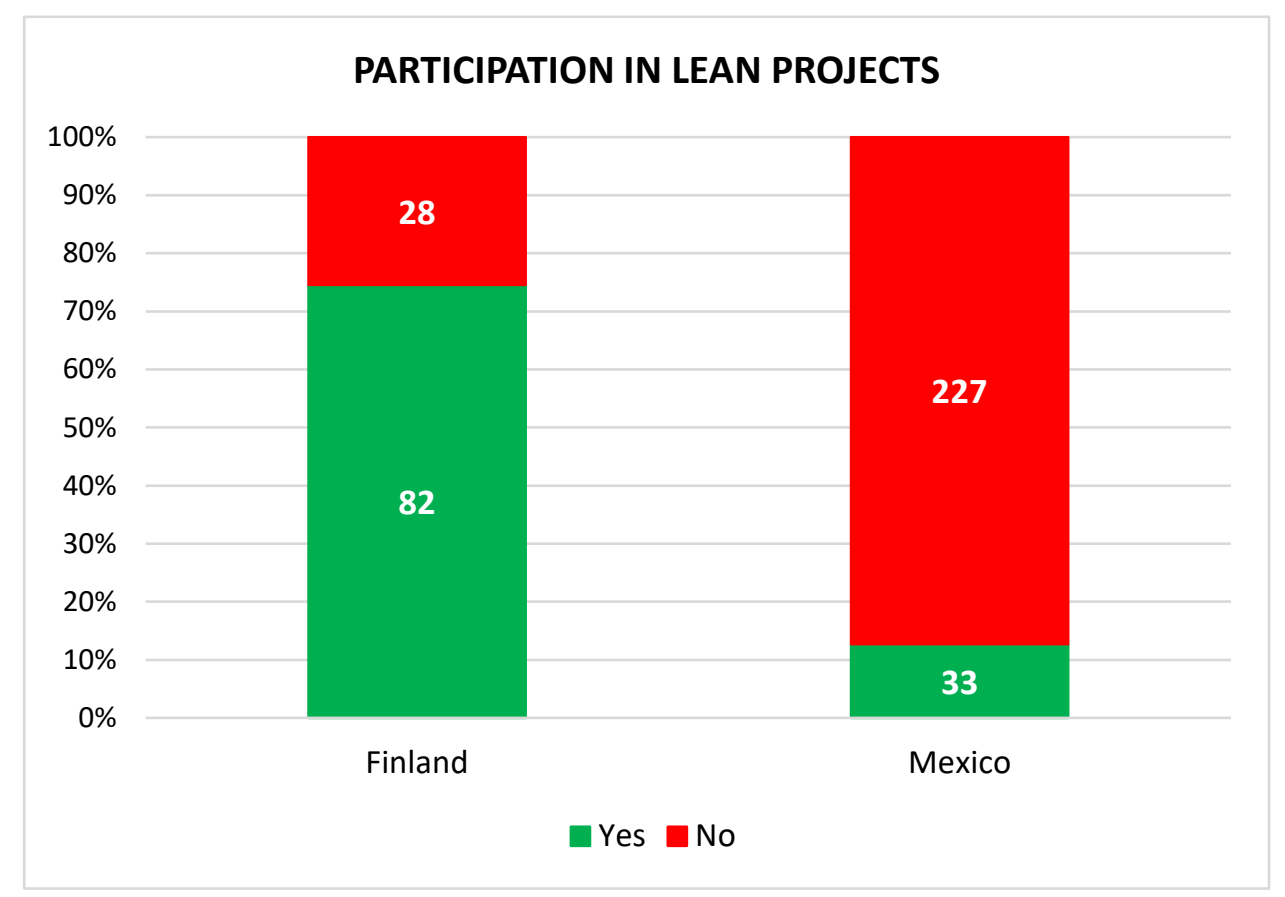

Figure 1. Percentage of respondents by participation in Lean projects.

Although some respondents have not participated in Lean projects (28 and 24 people in Finland and Mexico, respectively), most of the Finnish have knowledge about Lean thinking (Q2) and have considered its use (Q3). The opposite is the case of Mexican respondents, who do not know what Lean Thinking is about and then, have not considered its use.

Yet, when Lean tools are used, staff members may use them in an isolated manner without formally conducting Lean projects. Figure 2 exhibits the percentage of respondents that have knowledge of Lean tools in each country (Q4). Managers and supervisors also showed more knowledge about these than front-line workers. Other commonly used Lean 
tools, such as standardized work and process mapping, are not displayed since there is no information available from at least one of the countries to make a comparison.

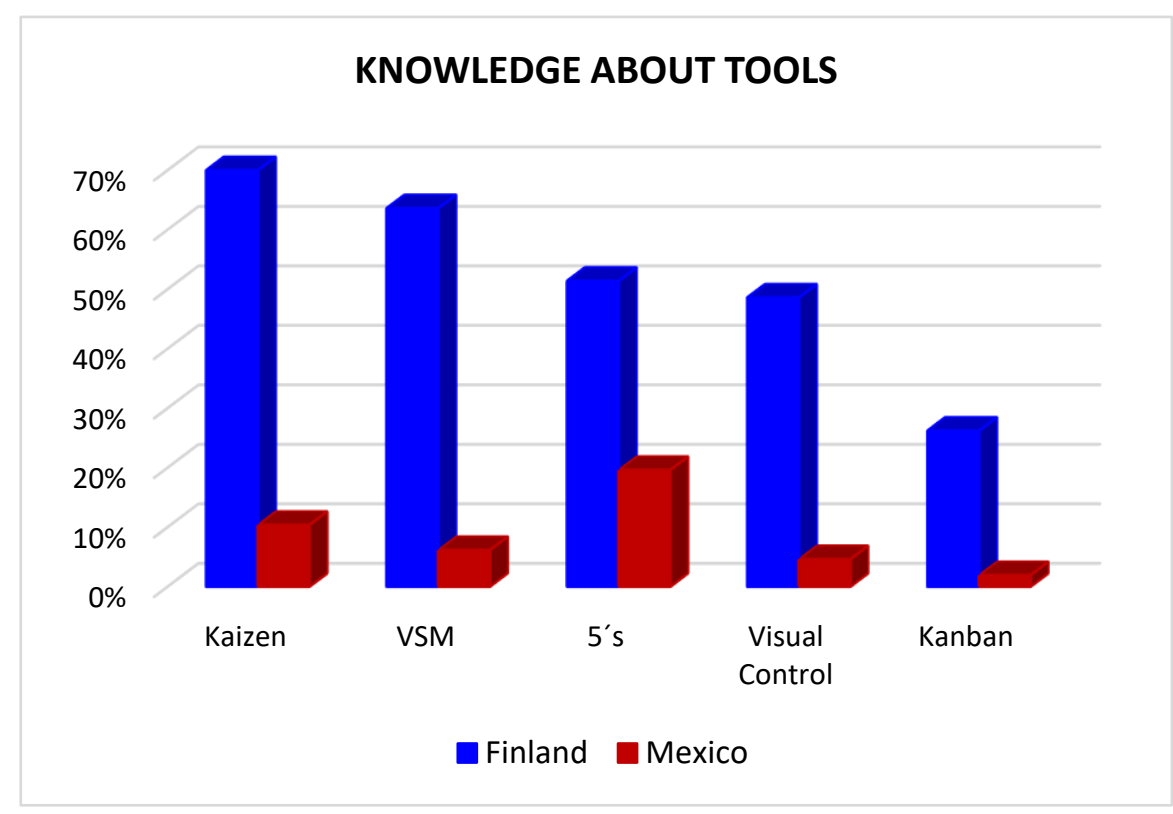

Figure 2. Percentage of respondents that have knowledge about Lean tools.

\subsection{Participating Respondents}

Responses to the second part of the survey are addressed as follows: first, questions 6, 7,8 , and 16, which relate to how projects started, are addressed; second, questions 9, 10, 11, 12 , and 13 about integration are shown; third, questions $14,15,17,18$, and 19 about benefits are addressed; and fourth, questions 20, 21, 22, and 23 about enabling/disabling factors are shown.

\subsubsection{Starting the Initiative}

First, Figure 3 displays responses about the estimated timing of the first project (Q6), which along with the professional group of people that introduced Lean $(\mathrm{Q} 8)$ were fairly similar between countries. Nonetheless, differences were found in the definition of specific and measurable goals from the beginning (Q16), as shown in Figure 4, and the reasons behind the introduction of Lean in the organizations (Q7). While the initial purpose of Lean healthcare in Finland was to reach financial savings, the purpose of the efforts in Mexico were exclusively oriented toward improving the quality of care. No difference was observed between managers/supervisors and front-line workers in any of the four questions. 


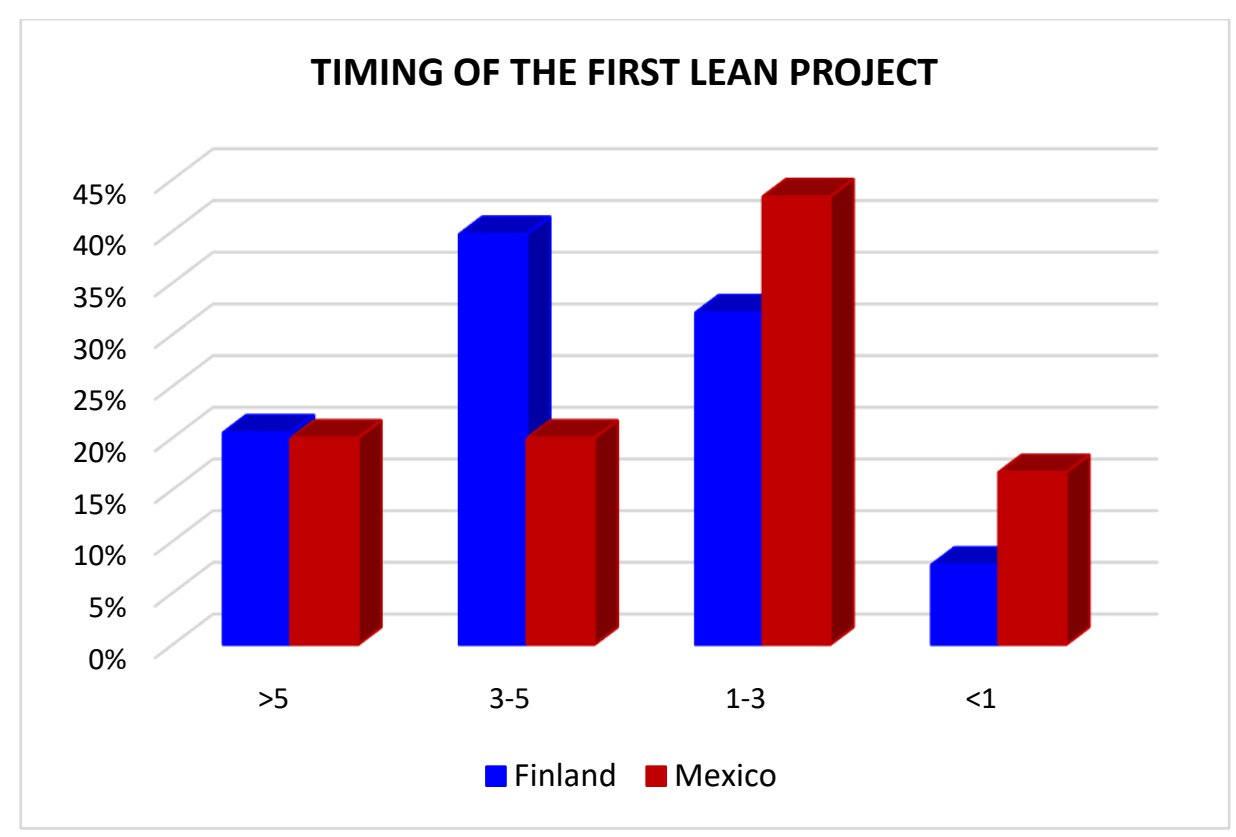

Figure 3. Percentage of responses by timing of the first Lean project.

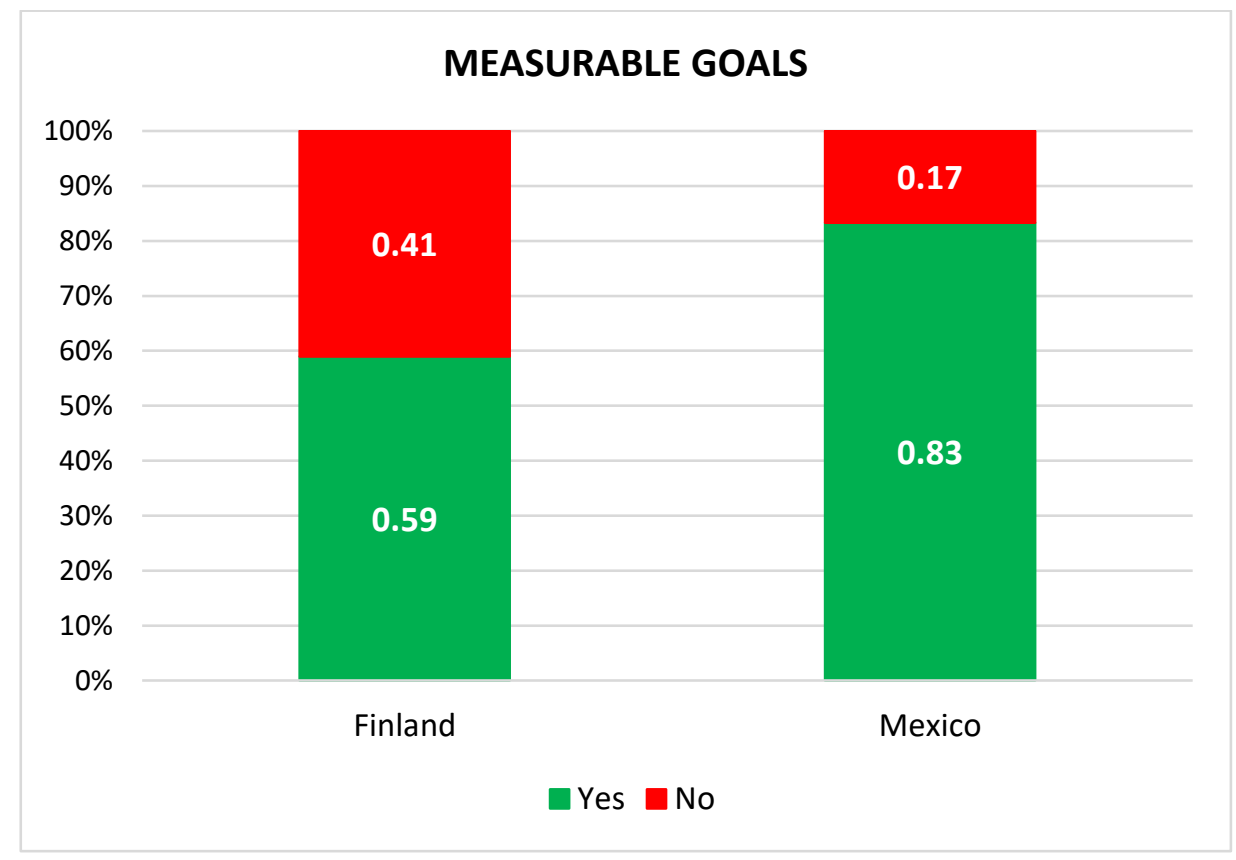

Figure 4. Percentage of responses about having measurable goals.

\subsubsection{Integration}

When investigating the maturity and level of integration of Lean initiatives in healthcare organizations, differences were found between countries in the tools used (Q13), which were more diverse in Finland, and whether these initiatives have incorporated internal Lean experts in the organizations (Q9), including their Lean background (Q10). Finnish healthcare institutions have more internal experts, though many of them are either selfeducated or had practical learning. On the contrary, similarities were identified in the number of Lean projects in which respondents have participated (Q11) and the level of integration of Lean practices (Q12), as per Figure 5. Additionally, no difference was found between managers/supervisors and front-line workers in any of the five questions. 


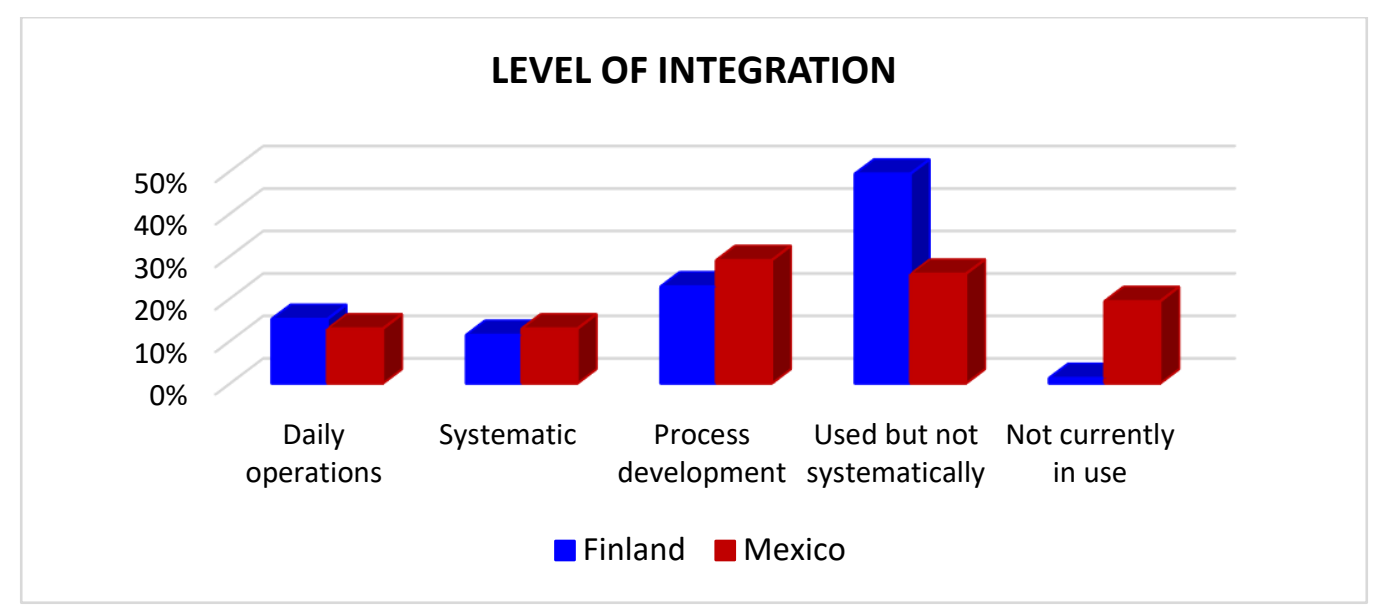

Figure 5. Percentage of responses by level of integration.

\subsubsection{Benefits}

Respondents were asked about their knowledge regarding the investment in Lean projects (Q14) and economic benefits brought by Lean initiatives (Q15). Although many Finnish respondents indicated some specific investment, results showed that most respondents $(84-100 \%)$ had no information and were unable to provide an answer regarding the economic benefits of conducting Lean projects. However, the strong perception about achieving goals $(\mathrm{Q} 17)$ and project success $(\mathrm{Q} 18)$ when conducting Lean projects was very high in both countries. The difference was found in the main benefits (Q19), which is consistent with (Q7) and shown in Figure 6. Conversely, differences were found between managers/supervisors and front-line workers in questions 17 through 19. Respondents that indicated goals were not achieved and projects were not successful were mainly front-line workers. Moreover, differences were observed between these groups when asked about the most important benefit brought by Lean: managers/supervisors tended to indicate economic savings, while most front-line workers indicated better quality of care.

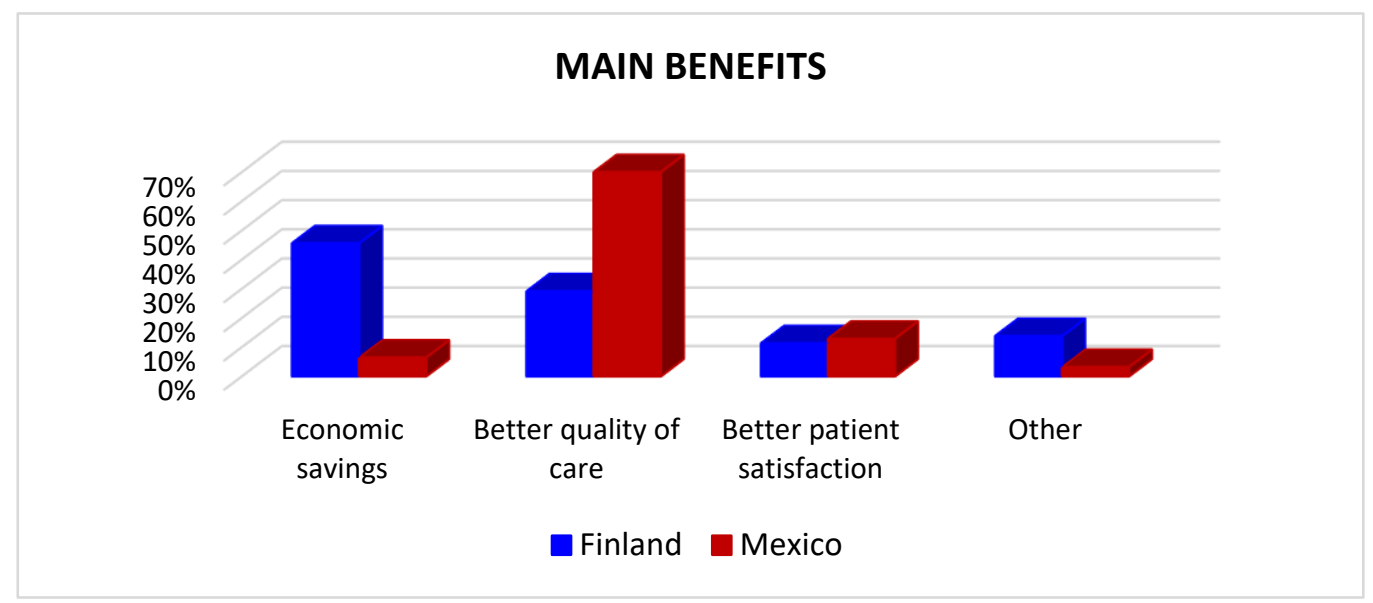

Figure 6. Percentage of responses regarding the main benefits of conducting Lean projects.

\subsubsection{Factors}

Similarities related to enabling and disabling factors for Lean (Q20 and Q21) were identified between healthcare professionals, with enabling factors shown in Figure 7. Although physicians were the least supportive group in both countries (Q22), the main reasons for resistance are different; while half of respondents in Mexico indicated that there is an critical lack of knowledge that limits their ability to conduct process improvement projects, the reasons for resistance in Finland are more diverse, with the will to maintain 
the old ways as the top reason (Q23). Finally, no difference was found between managers/ supervisors and front-line workers in any of the five questions.

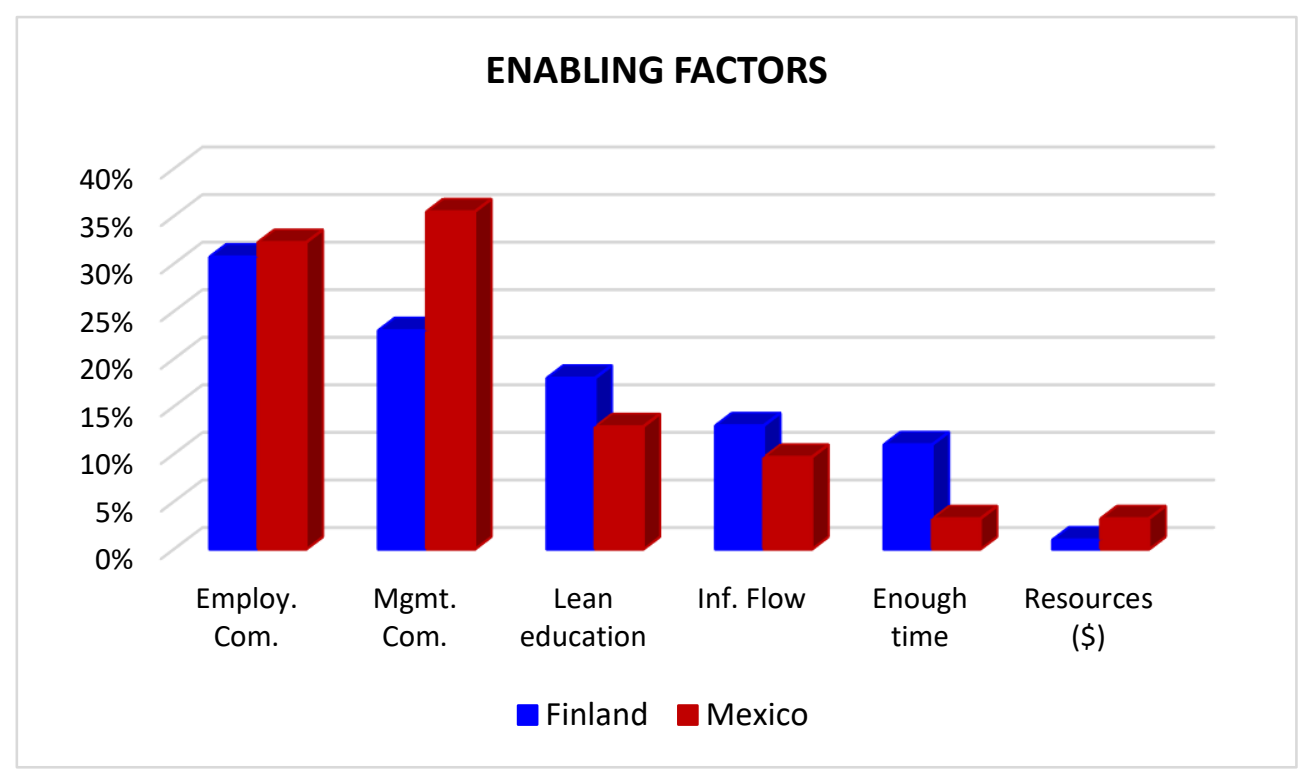

Figure 7. Percentage of responses regarding the enabling factors for Lean.

\section{Discussion}

Results indicated that the level at which Lean has been adopted in the Finnish healthcare system is greater than in Mexico. Still, there are some similarities in how Lean has been introduced and projects are conducted. Table 5 summarizes the statistical results for each question using Chi-square $\left(X^{2}\right)$, proportion $(p)$, and Wilcoxon signed-rank tests. The first column corresponds to the five groups of (research) questions in which results were presented; the second column denotes the question number in the questionnaire; column 3 summarizes the main idea of the question; column 4 indicates the statistical test; column 5 reports the P-value of the test, while column 6 indicates the conclusion derived from the test, both for comparing results from Finland vs Mexico; and finally, columns 7 and 8 present similar information for comparing results from middle-level managers and supervisors vs. front-line workers.

Finland $(75 \%)$ is ahead of Mexico (13\%) in the introduction of Lean in healthcare (Figure 1). Results also showed that Scandinavian healthcare professionals have more knowledge about Lean tools, wherein Kaizen and Value Stream Map (VSM) are the most popular in Finland, and $5 \mathrm{~S}$ was the top tool used in Mexico (Figure 2). There is also a clearer idea of the impact of Lean on patient processes in the Scandinavian country. Thus, Lean has had a greater penetration in the Finnish healthcare system, and the adoption level is greater in this country (RQ1). This result may seem obvious since the escalating cost of delivering care in Finland outnumbers Mexico by a ratio of approx. 440:1 (Finnish/Mexican total expenditure-Section 1), regardless of the inverse population ratio of 1:22. Furthermore, the Mexican culture is characterized by a cohesive hierarchical structure that may lock healthcare institutions into a state that may discourage any quest for new ways to manage and improve their processes. The lack of knowledge about Lean and the highly indulgent culture also allow current practices to be kept regardless of high costs and inefficiencies. 
Table 5. Summary of Results.

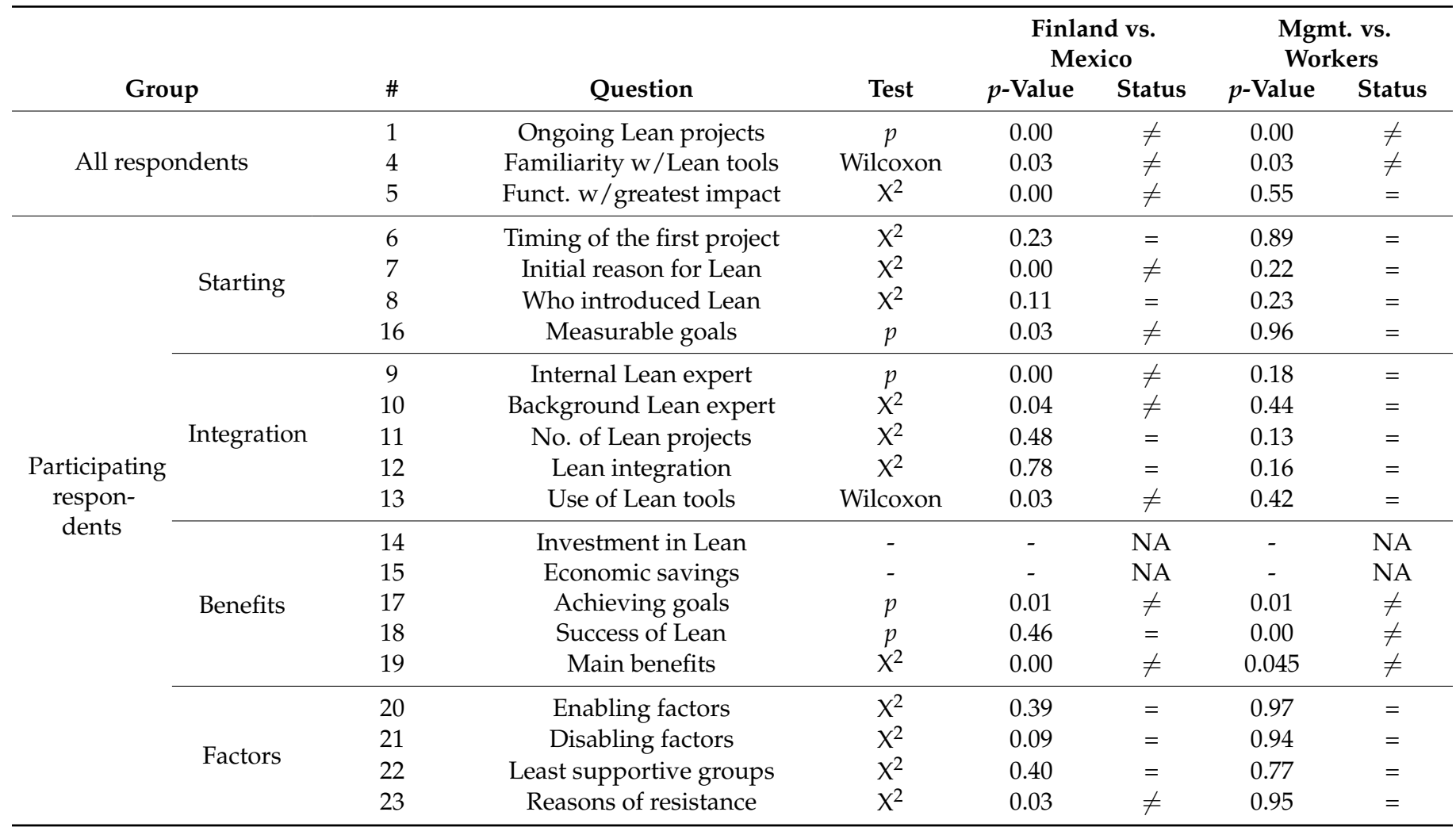

Likewise, managers and supervisors in both countries have been more involved in Lean projects and have more knowledge about Lean tools than front-line workers. This can be explained by the fact that managers have a wider view (and possibly more exposure) of what is happening in the organization and can be easily involved in Lean initiatives at least in an indirect way.

Once Lean is introduced, there are some similarities and differences in how healthcare institutions begin their Lean journey in both countries (RQ2). Similarities when initiating Lean are found in the following. First, the timing of the first Lean project was $1-5$ years in $63-72 \%$ of the cases and longer than five years ago in $21 \%$ of the cases in both countries (Figure 3); second, no particular group, top-management, supervisor level, front-line staff, etc., was significantly responsible for introducing Lean, despite a slight indication that top management is the group pushing these efforts in Mexico. On the contrary, a couple of differences were found, such as the initial reason for introducing Lean (supported by the benefits indicated in Figure 6), as well as the clear definition of specific and measurable goals since the outset (Figure 4). While the main drive for Lean is to reach economic savings in Finland, Lean initiatives in Mexico are driven by improving quality of care. This difference may lie on the individualist culture in Finland, with a focus on self- and family wellness only, vs. the collectivist culture in Mexico, where people look more for the group wellness including not just colleagues and workers, but possibly the care for patients. Additionally, an unexpected finding revealed that $79 \%$ of respondents in Mexico had well-defined, measurable goals when initiating Lean vs. 59\% in Finland. This suggests a better problem definition and project selection in Mexico, derived perhaps from the high uncertainty avoidance combined with limited resources to conduct daily work.

Concerning the integration and maturity of Lean (RQ3), results show similarities in the distribution of responses for the number of Lean projects, where $42-53 \%$ of respondents have taken part in two to five projects, and one fourth have taken part in only one project. Both countries are also similar in the poor integration of Lean in the organizations, as only one fourth of respondents indicated that Lean is conducted in a systematic way, as part of 
their operations strategy in some cases (Figure 5). This can be explained by the normative culture that both countries share, where a predominant short-term orientation characterizes how operations and projects are managed. Conversely, the first difference in this group was found that in that Finnish healthcare organizations have internal self-educated or practical-based Lean experts in most cases, which is not the case in Mexico. Furthermore, most projects in Mexico are mainly centered in the use of $5 \mathrm{~s}$, while respondents in Finland indicate a more varied use of concepts and tools, including Kaizen, Value Stream Map, 5s, and Visual Control.

When addressing benefits (RQ4), it was impossible to make a comparison of the initial investment and economic benefits brought by Lean, since the majority of respondents did not have information and could not provide an appropriate answer. Regarding the strong perception of achieving project goals and success, this was very high in both countries, with $100 \%$ in Finland and $81-82 \%$ in Mexico, even when the statistical test indicated a significant difference. The indulgent culture in Mexico may make tolerable the $19 \%$ of projects that did not achieve their goals. On the other hand, a remarkable difference lies in the outcome (Figure 6), which is consistent with the initial reason for deploying Lean. While the majority of Finnish healthcare professionals see Lean as a means to reduce costs and translate them into economic savings, their Mexican counterparts exclusively seek to improve the quality of care. Differences were also found between managers/supervisors and front-line workers. The first group perceived a higher level of accomplishment and higher rate of project success than front-line workers. This is a common example where managers tend to communicate more positive outcomes than those perceived by workers on the floor. Although most front-line workers still indicated a high level of accomplishment and project success, they usually have a more realistic perception about what happens in the operation. Furthermore, with a $p$-value $=0.045$, it was found that most managers perceived economic savings as the main benefit brought by Lean, while most workers responded that this was improving the quality of care. This is because managers have a more strategic view of the operation and have access to economic numbers. On the other hand, workers deal with patients every day, which gives them a closer look of how the quality of care is improved.

Lastly, when investigating the factors enabling and prohibiting successful Lean implementation in healthcare (RQ5), both Finnish and Mexican healthcare systems were very similar. The two most cited enabling factors in both countries were management and employee commitment (Figure 7), whereas disabling factors and barriers seemed to be more diverse in both cases, with no statistical difference, but an emphasis on insufficient time for projects by the Finnish study. As reported in the literature [5], results also showed that physicians represent the professional group that has shown the most resistance to change, with the top reasons for overall resistance being the lack of knowledge and the will to maintain the old conventions. This confirms Hofstede's results [6] about Finland and Mexico having normative cultures where people tend to keep traditions and norms. Regarding physicians, it is well-known that healthcare organizations work in hierarchical silos where physicians are usually at the top, making them less willing to lose autonomy. Particularly in Mexico, there is a highlighted lack of knowledge regarding Lean that may explain the small adoption rate reported earlier (13\%). It is evident that Lean is still in its infancy in Mexico and healthcare leaders lack the knowledge about how this approach can contribute to make their organizations more efficient and productive.

When contrasting these results with literature on Lean Manufacturing and cultural dimensions, it is hard to draw clear cut conclusions, as the promotion of Lean in healthcare is a result of different factors combined. While the 4th Global Manufacturing Research Group's survey indicated high uncertainty avoidance, short-term orientation, and low performance orientation (indulgence) as positive traits for Lean, and human orientation (masculinity/femininity), collectivism, and power distance as irrelevant [16], a second studied concluded that uncertainty avoidance, long-term orientation, and collectivism foster Lean, but masculinity and power distance inhibit Lean implementation and its sus- 
tainability, e.g., femininity and equal rights are better [18]. Hence, this study supports that a structure of equal rights (no hierarchy) is beneficial for implementing Lean. Moreover, under the assumption that lack of knowledge is the main limitation for using Lean in healthcare in Mexico, this study agrees that high uncertainty avoidance also allows for a better Lean deployment. Specific to the type of society, feminine (Finland) vs. masculine (Mexico), this research agrees with the second study that a feminine perspective is more convenient to deploy Lean successfully. On the contrary, when addressing the individualist (Finland) vs. collectivist (Mexico) dimension, drawing a one-way conclusion would be counterintuitive. This study supports the conclusion of the 4th Global Manufacturing Research Group's survey: this dimension has no direct effect in the introduction, promotion, and success of Lean; either way, healthcare institutions manage to conduct their Lean initiatives. However, it seems to influence the end goal of carrying out Lean initiatives: economic savings in an individualist society and improving the quality of care in a collectivism one. Similar is the case of the short- vs. long-term orientation, where previous studies derived contradictory conclusions. The results presented here indicate that both countries have normative, short-term orientations, and both are characterized by a lack of high-level and systematic integration of Lean initiatives. Although the conclusion may be that both orientations are positive for Lean purposes, a short-term perspective creates an environment where Lean projects are conducted as isolated and non-systematic initiatives, which, in turn, would suggest a systematic integration is reached through a long-term orientation.

\section{Conclusions}

This research has identified the similarities and differences in adopting and implementing Lean in healthcare between a developed, non-hierarchical, individualist, and feminine country such as Finland, and a developing, hierarchical, collectivist, and masculine country such as Mexico. Although Lean healthcare and its tools are more widely known, understood, and used in Finland than in Mexico, some general conclusions can be reached when linking these findings to the six dimensions that describe a national culture. Traits such as equal rights (no hierarchy), uncertainty avoidance, and feminine cultures (see Table 1) are positive for developing Lean initiatives. While there are no clear findings about the role of indulgence in supporting or obstructing Lean in healthcare, the individualist vs collectivist dimension seems to make a significant difference in the objectives of Lean; economic savings in an individualist society and improving the quality of care in a collectivism one. Finally, short- vs. long-term orientations can be positive for Lean purposes, as a short-term approach results in a weak level of integration and isolated initiatives, suggesting a systematic integration with a long-term orientation.

The main contribution of this work is providing an insight into how the six dimensions of national cultures can be linked to supporting or limiting Lean process improvement initiatives in healthcare organizations. Although this study does not aim to generalize the results across healthcare systems in countries around the globe, there are still many similarities between culturally different countries when conducting Lean projects, regardless of their population sizes and national healthcare expenditure. This suggests that many characteristics of Lean projects in healthcare may be universal across cultures and countries.

One limitation of this study may lie in the design of the measurement instrument used in both studies, given that it was not formally focused on metrics already established and explored in the literature. However, there are only a couple of survey studies assessing the adoption level of Lean in healthcare that already have a good acceptance in the literature [19], and the Finnish study was more suitable to be replicated in Mexico [20], allowing for a direct comparison between these two culturally different countries. A second limitation is that the Mexican study was conducted two years after the Finnish study, for which a two-year adjustment to Q6 was made to match both studies. However, the Mexican study still shows a smaller adoption level and general knowledge, which may suggest that any possible effect of this delay is minimal. 
Future research should focus on: (1) developing more individual and similar comparative studies with a focus on Lean (and possibly Six Sigma) in healthcare, through the lens of the cultural dimensions that characterize different countries; (2) studying the impact, integration, and sustainability aspects of previous and current Lean projects in these countries; and (3) creating and documenting better practices to introduce and spread the Lean concepts across the Mexican health system.

Author Contributions: Conceptualization, R.E.P.-G.; methodology, R.E.P.-G.; validation, R.E.P.-G. and T.J.; formal analysis, R.E.P.-G.; investigation, R.E.P.-G. and T.J.; resources, R.E.P.-G.; data curation, R.E.P.-G. and T.J.; writing-original draft preparation, R.E.P.-G.; writing—review and editing, R.E.P.G., T.J., L.E.C.-B., S.M.N.-G., and H.G.-R.; project administration, R.E.P.-G. All authors have read and agreed to the published version of the manuscript.

Funding: This research received no external funding.

Institutional Review Board Statement: Ethical review and approval were waived for this study, given that it did not collect any data regarding clinical human or animal subjects. This study makes a comparison between data collected in two previous studies already published in the literature.

Informed Consent Statement: Not applicable.

Data Availability Statement: Data available upon request.

Conflicts of Interest: The authors declare no conflict of interest.

\section{Appendix A}

Survey questions:

1. Do you have an ongoing (or have you had a) Lean project(s)?

- Yes

- No

If 'no', go to question 4

2. Do you know what Lean thinking is?

- Yes

- No

3. Have you considered using Lean thinking in your organization?

- Yes

- No

4. What Lean tools do you know? (multiple)

- Value stream mapping

- Kaizen

- 5's

- Kanban

- Visual control

- None of the above

5. In your opinion, where or in what healthcare functions does Lean thinking methodology have the greatest potential?

- Healthcare support functions (laundry, accounting, transportation, general administration, etc.)

- Healthcare functions indirectly involved in patient processes (pharmacy, laboratory, etc.)

- Patient processes / patient treatment processes

- Other.

For respondents that answered "Yes" to question 1: 
6. When did you first launch a Lean project?

- More than five years ago

- 3-5 years ago

- 1-3 years ago

- Less than one year ago

7. What was the initial reason for initiating Lean in your organization? (only one)

- Financial saving/increasing productivity

- Better quality of care/few errors

- Better patient satisfaction

- Other.

8. Who introduced the first Lean project in your organization? (only one)

- Member of the front-line staff (nurse, physician, technician, etc.)

- Supervisor level (chief nurse, chief physician, etc.)

- Middle-management (nurse manager, physician manager)

- Executive level / top management

- Somebody outside your organization

9. Do you have a Lean expert in your organization?

- Yes

- No

10. What is his/her educational background for Lean?

- Lean education or certification

- Related formal education at a general university or university of applied sciences (process engineering, etc.)

- 'Self-educated' by means of literature, seminars and in practice

- 'Practical' learning (managing or taking part in Lean projects)

- $\mathrm{N} / \mathrm{A}$

11. How many Lean project have you had in your organization?

- More than 10

- $6-10$

- $2-5$

- One

12. In your opinion, how has Lean been implemented in your organization?

- Lean thinking is a part of our organization's daily operations (management system and methodology)

- Lean thinking is systematic, but is not included as part of daily operations/ management (methodology)

- Lean thinking is part of process development (methodology)

- Lean thinking is used in our organization but not systematically

- Lean thinking has been used, but is not currently in use

13. What Lean methods have you used in your organization/unit? (multiple)

- Value stream mapping

- Kaizen

- 5's

- Kanban

- Visual control

14. What is the amount of money invested in your Lean project(s)?

- More than $\$ 630,000$ Mexican pesos- $€ 30,000$

- $\$ 336,000-\$ 630,000$ Mexican pesos- $€ 16,000-30,000$ 
- $\$ 105,000-\$ 336,000$ Mexican pesos- $€ 5000-15,999$

- Less than $\$ 105,000$ Mexican pesos- $€ 5000$

- No money invested/done in daily work

- Unknown

15. What (if measured) is the amount of money saved with Lean project(s)?

- More than $\$ 10.5$ million Mexican pesos- $€ 500,000$

- $\quad \$ 5.2$ million- $\$ 10.5$ million Mexican pesos- $€ 251,000-500,000$

- $\quad \$ 2.1$ million-\$5.2 million Mexican pesos- $€ 101,000-250,000$

- $\$ 1$ million-\$2.1 million Mexican pesos- $€ 50,000-100,000$

- Less than $\$ 1$ million Mexican pesos- $€ 50,000$

- Unknown

16. Do you or did you require specific or measurable goals when initiating (when you initiated) your first Lean project?

- Yes

- No

17. Did your first project achieve its goals?

- Yes

- No

18. In your opinion, have Lean project(s) been successful in your organization?

- Yes

- No

19. What is the most important benefit that Lean thinking has brought to your organization?

- Economic savings/better productivity

- Better quality of care/fewer treatment errors

- Better patient satisfaction

- Other, what?

20. What were the enabling factors for Lean project?

- Committed management

- Committed employees

- Good financial resources

- $\quad$ Enough time for projects

- Lean education

- Good flow of information

- Other, what?

21. What were the disabling factors for Lean project?

- Lack of commitment of management

- $\quad$ Lack of committed employees

- Lack of financial resources

- Insufficient time for project

- Insufficient training in Lean

- Inappropriate flow of information

- Other.

22. Which professional group (if it can be specified) was the least supportive of your organization's Lean project(s)?

- Nurses

- Physicians

- Other personnel involved in patient/treatment processes (including but not limited to healthcare assistants, lab technicians, etc.). 
- Supervisors

- Middle management

- Executive management

23. What are (in your opinion) the reasons for resistance to Lean projects?

- Tired of development projects

- Lack of knowledge

- The will to maintain old ways to do things

- Discrepancies between professional groups

- Negative experiences from previous Lean initiatives

- Other.

Appendix B Responses by Management vs. Workers Groups

Table A1. Responses to questions 1-8 by management vs. front-line workers.

\begin{tabular}{|c|c|c|c|c|c|c|c|c|c|c|c|c|c|c|c|c|}
\hline \multirow[b]{2}{*}{ Count. } & \multicolumn{2}{|c|}{ Q1 } & \multicolumn{2}{|c|}{ Q2 } & \multicolumn{2}{|c|}{ Q3 } & \multicolumn{2}{|c|}{ Q4 } & \multicolumn{2}{|c|}{ Q5 } & \multicolumn{2}{|c|}{ Q6 } & \multicolumn{2}{|c|}{ Q7 } & \multicolumn{2}{|c|}{ Q8 } \\
\hline & Mgm & Work & Mgm & Work & Mgm & Work & Mgm & Work & Mgm & Work & Mgm & Work & Mgm & Work & Mgm & Work \\
\hline Yes & $50 \%$ & $24 \%$ & $46 \%$ & $14 \%$ & $56 \%$ & $38 \%$ & & & & & & & & & & \\
\hline No & $50 \%$ & $76 \%$ & $54 \%$ & $86 \%$ & $44 \%$ & $62 \%$ & & & & & & & & & & \\
\hline $\mathrm{a}$ & & & & & & & 43 & 41 & $12 \%$ & $12 \%$ & $12 \%$ & $10 \%$ & $54 \%$ & $37 \%$ & $15 \%$ & $25 \%$ \\
\hline b & & & & & & & 49 & 53 & $10 \%$ & $15 \%$ & $31 \%$ & $27 \%$ & $34 \%$ & $47 \%$ & $15 \%$ & $26 \%$ \\
\hline c & & & & & & & 42 & 64 & $75 \%$ & $70 \%$ & $37 \%$ & $44 \%$ & $8 \%$ & $10 \%$ & $21 \%$ & $18 \%$ \\
\hline d & & & & & & & 18 & 15 & $3 \%$ & $2 \%$ & $20 \%$ & $19 \%$ & $4 \%$ & $5 \%$ & $33 \%$ & $21 \%$ \\
\hline e & & & & & & & 31 & 33 & & & & & & & $17 \%$ & $10 \%$ \\
\hline $\begin{array}{l}\text { Total } \\
\text { Resp. }\end{array}$ & 103 & 267 & 54 & 197 & 48 & 186 & 102 & 263 & 73 & 84 & 49 & 59 & 48 & 61 & 48 & 61 \\
\hline
\end{tabular}

Table A2. Responses to questions $9-16$ by management vs. front-line workers.

\begin{tabular}{|c|c|c|c|c|c|c|c|c|c|c|c|c|c|c|c|c|}
\hline \multirow[b]{2}{*}{ Count. } & \multicolumn{2}{|c|}{ Q9 } & \multicolumn{2}{|c|}{ Q10 } & \multicolumn{2}{|c|}{ Q11 } & \multicolumn{2}{|c|}{ Q12 } & \multicolumn{2}{|c|}{ Q13 } & \multicolumn{2}{|c|}{ Q14 } & \multicolumn{2}{|c|}{ Q15 } & \multicolumn{2}{|c|}{ Q16 } \\
\hline & Mgm & Work & Mgm & Work & Mgm & Work & Mgm & Work & Mgm & Work & Mgm & Work & Mgm & Work & Mgm & Work \\
\hline Yes & $71 \%$ & $59 \%$ & & & & & & & & & & & & & $66 \%$ & $66 \%$ \\
\hline No & $29 \%$ & $41 \%$ & & & & & & & & & & & & & $34 \%$ & $34 \%$ \\
\hline $\mathrm{a}$ & & & $23 \%$ & $19 \%$ & $13 \%$ & $12 \%$ & $20 \%$ & $10 \%$ & 23 & 24 & $8 \%$ & $7 \%$ & $0 \%$ & $0 \%$ & & \\
\hline b & & & $28 \%$ & $21 \%$ & $22 \%$ & $16 \%$ & $14 \%$ & $10 \%$ & 23 & 23 & $21 \%$ & $2 \%$ & $4 \%$ & $0 \%$ & & \\
\hline c & & & $40 \%$ & $38 \%$ & $52 \%$ & $40 \%$ & $18 \%$ & $30 \%$ & 21 & 32 & $10 \%$ & $4 \%$ & $2 \%$ & $3 \%$ & & \\
\hline $\mathrm{d}$ & & & $25 \%$ & $45 \%$ & $13 \%$ & $33 \%$ & $48 \%$ & $38 \%$ & 4 & 6 & $6 \%$ & $4 \%$ & $2 \%$ & $0 \%$ & & \\
\hline e & & & $20 \%$ & $26 \%$ & & & $0 \%$ & $12 \%$ & 14 & 12 & $23 \%$ & $18 \%$ & $8 \%$ & $3 \%$ & & \\
\hline $\mathrm{f}$ & & & & & & & & & & & $31 \%$ & $65 \%$ & $84 \%$ & $93 \%$ & & \\
\hline $\begin{array}{l}\text { Total } \\
\text { Resp. }\end{array}$ & 49 & 59 & 40 & 42 & 46 & 58 & 50 & 60 & 48 & 61 & 48 & 55 & 50 & 58 & 50 & 58 \\
\hline
\end{tabular}

Table A3. Responses to questions 17-23 by management vs. front-line workers.

\begin{tabular}{|c|c|c|c|c|c|c|c|c|c|c|c|c|c|c|}
\hline \multirow[b]{2}{*}{ Count. } & \multicolumn{2}{|c|}{ Q17 } & \multicolumn{2}{|c|}{ Q18 } & \multicolumn{2}{|c|}{ Q19 } & \multicolumn{2}{|c|}{ Q20 } & \multicolumn{2}{|c|}{ Q21 } & \multicolumn{2}{|c|}{ Q22 } & \multicolumn{2}{|c|}{ Q23 } \\
\hline & Mgm & Work & Mgm & Work & Mgm & Work & Mgm & Work & Mgm & Work & Mgm & Work & Mgm & Work \\
\hline Yes & $100 \%$ & $88 \%$ & $96 \%$ & $79 \%$ & & & & & & & & & & \\
\hline No & $0 \%$ & $12 \%$ & $4 \%$ & $21 \%$ & & & & & & & & & & \\
\hline $\mathrm{a}$ & & & & & $46 \%$ & $25 \%$ & $63 \%$ & $48 \%$ & $15 \%$ & $15 \%$ & $16 \%$ & $20 \%$ & $29 \%$ & $25 \%$ \\
\hline $\mathrm{b}$ & & & & & $32 \%$ & $52 \%$ & $75 \%$ & $66 \%$ & $29 \%$ & $23 \%$ & $49 \%$ & $43 \%$ & $41 \%$ & $46 \%$ \\
\hline c & & & & & $10 \%$ & $13 \%$ & $0 \%$ & $5 \%$ & $29 \%$ & $18 \%$ & $19 \%$ & $17 \%$ & $51 \%$ & $54 \%$ \\
\hline $\mathrm{d}$ & & & & & $12 \%$ & $10 \%$ & $25 \%$ & $21 \%$ & $58 \%$ & $45 \%$ & $8 \%$ & $7 \%$ & $18 \%$ & $20 \%$ \\
\hline $\mathrm{e}$ & & & & & & & $38 \%$ & $38 \%$ & $33 \%$ & $18 \%$ & $0 \%$ & $6 \%$ & $2 \%$ & $0 \%$ \\
\hline $\mathrm{f}$ & & & & & & & $31 \%$ & $25 \%$ & $21 \%$ & $17 \%$ & $8 \%$ & $7 \%$ & $6 \%$ & $7 \%$ \\
\hline $\mathrm{g}$ & & & & & & & $6 \%$ & $8 \%$ & $13 \%$ & $7 \%$ & & & & \\
\hline $\begin{array}{l}\text { Total } \\
\text { Resp. }\end{array}$ & 31 & 41 & 47 & 57 & 50 & 60 & 48 & 61 & 48 & 60 & 37 & 54 & 49 & 61 \\
\hline
\end{tabular}




\section{References}

1. Brackett, T.; Comer, L.; Whichello, R. Do Lean Practices Lead to More Time at the Bedside? J. Healthc. Qual. 2013, 35, 7-14. [CrossRef]

2. D'Andreamatteo, A.; Ianni, L.; Lega, F.; Sargiacomo, M. Lean in healthcare: A comprehensive review. Health Policy 2015, 119, 1197-1209. [CrossRef] [PubMed]

3. Poksinska, B. The Current State of Lean Implementation in Health Care: Literature Review. Qual. Manag. Health Care 2010, 19, 319-329. [CrossRef] [PubMed]

4. Grout, J.R.; Toussaint, J.S. Mistake-proofing healthcare: Why stopping processes may be a good start. Busi Horiz 2010, 53, 149-156. [CrossRef]

5. Barnas, K. ThedaCare's business performance system: Sustaining continuous daily improvement through hospital management in a lean environment. Jt. Comm J. Qual. Saf. 2011, 37, 387-399. [CrossRef]

6. Furman, C.; Caplan, R. Applying the Toyota Production System: Using a patient safety alert system to reduce error. Jt. Comm J. Qual. Saf. 2007, 33, 376-386. [CrossRef]

7. Nelson-Peterson, D.L.; Leppa, C.J. Creating an environment for caring using lean principles of the Virginia Mason Production System. J. Nurs. Adm. 2007, 37, 287-294. [CrossRef] [PubMed]

8. Ben-Tovim, D.I.; Bassham, J.E.; Bolch, D.; Martin, M.A.; Dougherty, M.; Szwarcbord, M. Lean thinking across a hospital: Redesigning care at the Flinders Medical Centre. Aust. Health Rev. 2007, 31, 10-15. [CrossRef] [PubMed]

9. Ben-Tovim, D.I.; Bassham, J.E.; Bennett, D.M.; Dougherty, M.L.; Martin, M.A.; O’Neill, S.J.; Sincock, J.L.; Szwarcbord, M.G. Redesigning care at the Flinders Medical Centre: Clinical process redesign using "lean thinking". Med. J. Aust. 2008, 188, 27-31. [CrossRef]

10. Burgess, N.; Radnor, Z. Evaluating Lean in healthcare. Int. J. Health Care Qual. Assur. 2013, 26, 220-235. [CrossRef]

11. Woodnutt, S. Is Lean sustainable in today's NHS hospitals? A systematic literature review using the meta-narrative and integrative methods. Int. J. Health Care Qual. Assur. 2018, 30, 578-586. [CrossRef]

12. Graban, M. Lean Hospitals: Improving Quality, Patient Safety, and Employee Engagement, 3rd ed.; CRC Press: New York, NY, USA, 2016.

13. Peimbert-García, R.E.; Matis, T.; Cuevas-Ortuño, J.; and Nucamendi-Guillen, S.M. Systematic Review of Literature on Lean and Six Sigma in Healthcare and Directions for Future Research. In Proceedings of the 10th International Conference on Industrial Engineering and Operations Management (IEOM), Dubai, UAE, 10-12 March 2020.

14. Hofstede, G.; Hofstede, G.J. Culture and Organizations: Software of the Mind, 2nd ed.; McGrawHill: New York, NY, USA, 2005.

15. Hofstede, G. Dimensionalizing cultures: The Hofstede model in context. Online Read. Psychol. Cult. 2011, 2, 1-8. [CrossRef]

16. Kull, T.J.; Yan, T.; Liu, Z.; Wacker, J.G. The moderation of lean manufacturing effectiveness by dimensions of national culture: Testing practice-culture congruence hypotheses. Int. J. Prod. Econ. 2014, 153, 1-12. [CrossRef]

17. Machado-Guimararâes, C.; Crespo de Carvalho, J. Lean Healthcare across Cultures: State-Of-The-Art. Am. Int. J. Contemp. Res. 2012, 2, 187-206.

18. Erthal, A.; Marques, L. National culture and organisational culture in lean organisations: A systematic review. Prod. Plan. Control. 2018, 29, 668-687. [CrossRef]

19. Jorma, T.; Tiirinki, H.; Bloigu, R.; Turkki, L. LEAN thinking in Finnish healthcare. Leadersh. Health Serv. 2016, 29, 9-36. [CrossRef] [PubMed]

20. Peimbert-García, R.E.; Matis, T.; Beltran-Godoy, J.H.; Garay-Rondero, C.L.; Vicencio-Ortiz, J.C.; Lopez-Soto, D. Assessing the State of Lean and Six Sigma Practices in Healthcare in Mexico. Leadersh. Health Serv. 2019, 32, 644-662. [CrossRef]

21. Statistics Finland. Health Expenditure and Financing. Available online: http://www.stat.fi/til/thkura/index_en.html (accessed on 4 March 2020).

22. Finnish Institute for Health and Welfare Personnel in the Health Care and Social Welfare. Available online: https://thl.fi/en/ web/thlfi-en (accessed on 5 March 2020).

23. INEGI. National Institute of Statistics and Geography. Available online: https:/ / en.www.inegi.org.mx (accessed on 6 March 2020).

24. Womack, J.P.; Jones, D.T. Lean Thinking: Banish Waste and Create Wealth in Your Corporation, 2nd ed.; Free Press: New York, NY, USA, 2003.

25. Costa, L.B.M.; Folho, M.G. Lean healthcare: Review, classification and analysis of literature. Prod. Plan. Control. 2016, 27, 823-836. [CrossRef]

26. Henrique, D.B.; Filho, M.G. A systematic literature review of empirical research in Lean and Six Sigma in healthcare. Total Qual. Manag. Bus. Excell. 2020, 31, 429-449. [CrossRef]

27. Tlapa, D.; Zepeda-Lugo, C.A.; Tortorella, G.L.; Baez-Lopez, Y.A.; Limon-Romero, J.; Alvarado-Iniesta, A.; Rodriguez-Borbon, M.I. Effects of lean healthcare on patient flow: A systematic review. Value Health 2020, 23, 260-273. [CrossRef]

28. Khodambashi, S. Alignment of an intra-operating management process to a health information system: A Lean analysis approach. Pers. Ubiquitous Comput. 2015, 19, 689-698. [CrossRef]

29. Savage, C.; Parke, L.; von Knorring, M.; Mazzocato, P. Does lean muddy the quality improvement waters? A qualitative study of how a hospital management team understands lean in the context of quality improvement. BMC Health Serv. Res. 2016, 16, 588-597. [CrossRef] [PubMed] 
30. Ulhassan, W.; Sandahl, C.; Westerlund, H.; Henriksson, P.; Bennermo, M.; Scharwz, U.T.; Thor, J. Antecedents and Characteristics of Lean Thinking Implementation in a Swedish Hospital: A Case Study. Qual. Manag. Health Care 2013, 22, 48-61. [CrossRef] [PubMed]

31. Setijono, D.; Naraghi, A.M.; Ravipati, U.P. Decision support system and the adoption of lean in a Swedish emergency ward: Balancing supply and demand towards improved value stream. Int. J. Lean Six Sigma 2010, 1, 234-248. [CrossRef]

32. Larsson, A.; Johansson, M.; Baathe, F.; Neselius, S. Reducing throughput time in a service organisation by introducing crossfunctional teams. Prod. Plan. Control. 2012, 23, 571-580. [CrossRef]

33. Mazzocato, P.; Holden, R.J.; Brommels, M.; Aronsson, H.; Backman, U.; Elg, M.; Thor, J. How does lean work in emergency care? A case study of a lean-inspired intervention at the Astrid Lindgren Children's hospital, Stockholm, Sweden. BMC Health Serv. Res. 2012, 12, 28-40. [CrossRef] [PubMed]

34. Edwards, K.; Nielsen, A.P.; Jacobsen, P. Implementing lean in surgery-lessons and implications. Int. J. Technol. Manag. 2012, 57, 4-17. [CrossRef]

35. Andersen, H.; Røvik, K.A. Lost in translation: A case-study of the travel of lean thinking in a hospital. BMC Health Serv. Res. 2015, 15, 401-410. [CrossRef]

36. Hasle, P.; Anders, P.N.; Edwards, K. Application of Lean Manufacturing in Hospitals—the Need to Consider Maturity, Complexity, and the Value Concept. Hum. Factor Ergon. Manuf. 2016, 26, 430-442. [CrossRef]

37. Johannessen, K.A.; Alexandersen, N. Improving accessibility for outpatients in specialist clinics: Reducing long waiting times and waiting lists with a simple analytic approach. BMC Health Serv. Res. 2018, 18, 827-830. [CrossRef]

38. Hihnala, S.; Kettunen, L.; Suhonen, M.; Tiirinki, H. The Finnish healthcare services lean management: Health services managers' experiences in a special health care unit. Leadersh. Health Serv. 2018, 31, 17-32. [CrossRef] [PubMed]

39. Maijala, R.; Eloranta, S.; Reunanen, T.; Ikonen, T.S. Successful implementation of Lean as a managerial principle in health care: A conceptual analysis from systematic literature review. Int. J. Technol. Assess. Health Care 2018, 34, 134-146. [CrossRef]

40. Ruohoaho, U.M.; Kokki, M.; Hirvonen, J.; Joukainen, S.; Aaltomaa, S.; Fraunberg, M.; Leinonen, V.; Reijula, J. Value stream map assessment of the extended day: 23h surgery model. Intell Build. Int. 2018, 1-15. [CrossRef]

41. da Silva, I.B.; Seraphim, E.C.; Agostinho, O.L.; Lima, J.O.F.; Batalha, G.F. Lean office in health organization in the Brazilian Army. Int. J. Lean Six Sigma 2015, 6, 2-16. [CrossRef]

42. Filho, M.G.; Boschi, A.; Rentes, A.F.; Thurer, M.; Bertani, T.M. Improving hospital performance by use of lean techniques: An action research project in Brazil. Qual. Eng. 2015, 27, 196-211. [CrossRef]

43. Peimbert-García, R.E. Analysis and Evaluation of Reviews on Lean and Six Sigma in Healthcare. Qual. Manag. Health Care 2019, 28, 229-236. [CrossRef]

44. Zepeda-Lugo, C.; Tlapa, D.; Baez-Lopez, Y.; Limon-Romero, J.; Ontiveros, S.; Perez-Sanchez, A.; Tortorella, G. Assessing the impact of lean healthcare on inpatient care: A systematic review. Int. J. Environ. Res. Public Health 2020, 17, 5609. [CrossRef] [PubMed]

45. Peimbert-García, R.E.; Gutiérrez-Mendoza, L.M.; García-Reyes, H. Applying Lean Healthcare to Improve the Discharge Process in a Mexican Academic Medical Center. Sustainability 2021. Accepted for Publication. 